\section{Biogeography $3^{\text {rd }}$ edition}

Mark V. Lomolino, Brett R. Riddle and James H. Brown. 2005. ISBN 0-87893-062-0 Sinauer Associates Inc. Publishers. \$US 89.95+shipping. Contact: publish@sinauer.com

$\mathbf{T}$ his book was first published in 1983 and is one of the "most comprehensive text and general reference books in the field." The third edition builds on the strengths of its two previous editions, combing evolutionary and ecological perspectives to show how Earth history, contemporary environments, and evolutionary and ecological processes have shaped species distributions and nearly all patterns of biodiversity. It is an empirically and conceptually rich text that illustrates general patterns and processes using examples from a diversity of plants and animals across the world's aquatic and terrestrial ecosystems.
Biogeography is written as a primary text for undergraduates and graduate courses, and is also an invaluable reference for biogeographers, ecologists, evolutionary biologists and conservation biologists. It starts from simple facts and principles and assuming only a rudimentary knowledge of biology, geography and Earth history, the text explains the relationships between geographic variation in biodiversity and the geological, ecological and evolutionary processes that have produced them. It is written in an engaging style and emphasizes the interplay between unifying concepts and presents evidence that supports or challenges these

\title{
Diseases of Trees and Shrubs $2^{\text {nd }}$ edition
}

Wayne A. Sinclair \& Howard H. Lyon. 2005. ISBN 0-8014-4371-7

Cornell University Press \$ US 85.00 + shipping. Contact: JLH98@cornell.edu

irst published in 1987, Diseases of Trees and Shrubs has become a standard reference for plant health specialists, plant diagnosticians, horticulturists, arborists, foresters and their students. Now thoroughly revised, fully updated, and illustrated with more than 2,200 digitally optimized colour images in 261 full-colour plates and more than 350 black-and-white photographs and drawings, this second edition is an unrivalled survey of the diseases of forest and shade trees and woody ornamental plants in the United States and Canada.
The book is both an authoritative reference book and a powerful diagnostic tool. Organized according to the type of disease-inducing agent, the second edition is also designed to be helpful in classroom and field instruction. Symptoms, signs and cycles of hundreds of diseases are described and microscopic features of many pathogens are depicted in photos and line drawings. A searchable CD-ROM included with the book contains bibliographic entries for more than 4,500 works that readers can consult for additional information or

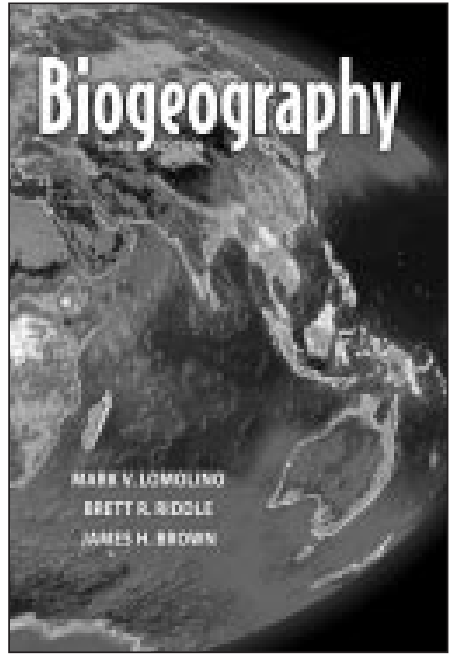

concepts. This edition has been completely revised and updated, covering many emerging topics and including case studies and insights from over 1,000 recent studies of the geography of nature.

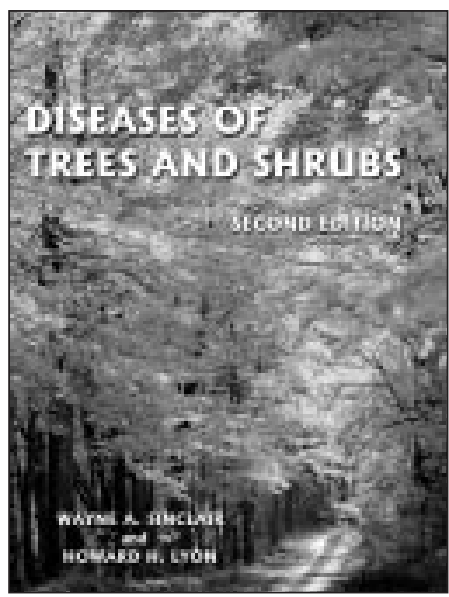

images. "This remarkable scholarly work - praised as one of the best horticultural books of the twentieth century - lays claim to the same accolade for the twenty-first century."

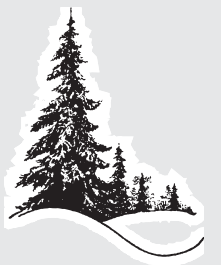

Editor's Note The CIF/IFC national office receives several excellent publications throughout the year. These will be announced to our readers. Reviewers are needed. We have only one copy of any publication and it is yours to keep or donate to a forestry faculty or college of your choice. If you are interested in reviewing a book, please contact the national office. E-mail: cif@cif-ifc.org 